\title{
Hioneering large diamond recovery at Karowe diamond mine
}

\author{
by L.M. van Niekerk* , A. Olivier ${ }^{\dagger}$, J. Armstrong ${ }^{\ddagger}$, and
}

N.A. Sikwa\$

\section{Synopsis}

Historically, the recovery of large diamonds in conventional treatment plant flow sheets has been associated with dense media separation (DMS). This is attributed mainly to DMS's highly efficient and proven track record in the concentration and separation of ores with variable solids densities. In most instances, DMS has been utilized as a pre-concentration step ahead of any recovery plant, due to its ability and versatility in reducing feed within a specific size range to manageable volumes for downstream $\mathrm{X}$-ray processing and subsequent diamond recovery. The benefit of using carbon-signature-based detection equipment for retrieving large stones upfront in the flow sheet not only equates to earlier recovery of diamonds from the system, but also lessens the exposure of diamond-bearing ore to additional materials handling, pumping, and/or crushing, which has been known to damage or even break diamonds and decrease revenue.

Keywords

diamond recovery, preconcentration, sorting, X-ray transmission.

\section{Introduction}

The selection of X-ray transmission (XRT) technology for kimberlite sorting lies in the advantage of the material presentation.

Detection with XRT is dependent on the atomic number of the material. The sorting ability and effectiveness of XRT is based on the difference in the atomic numbers of the materials that need to be separated. The advantage of this technique is that the presentation of the material is of lesser importance. Unlike nearinfrared (NIR) and X-ray luminescence (XRL), $\mathrm{XRT}$ is not dependent on a visible colour difference or clean, reflective particle surfaces. XRT technology has a significantly higher detection rate for Type II diamonds compared to traditional XRL sorters, with an order-ofmagnitude lower concentrate yield percentage. XRT sorters deliver a significantly lower percentage yield than traditional DMS plants, with a vastly reduced running costs relating to consumables and utilities. Figure 1 summarizes the characteristics of the various sorting technologies and their applications.

A broadband electrical X-ray beam is impinged on the material to be sorted (Riedel and Dehler, 2010) while it is moving along a belt (Figure 2). The X-ray sensor system below the material produces a digital image of the material being sorted, using two different energy bands (Figure 3). The X-ray attenuation through the material is different for the two bands and depends on the material's thickness and density. A transformation of the density images of the two bands then enables the classification of each pixel according to the average atomic density of the particle (Figure 4).

Each pixel is classified relative to a reference density against which the system has been calibrated. A complete particle will then be classified according to the overall classification of the pixels within the particle. Depending on the classification, the selected particles are either 'ejects', diverted upwards by air jets out of the overall material stream (material stream B) or 'accepts' in the other stream (material stream A) (Figure 5). It is important to note that 'eject' refers to the material that the system has been configured to blow out of the material stream; this can be either the waste or the product.

\section{XRT circuit design, commissioning, and performance}

The Karowe XRT section, part of the greater Karowe Plant Upgrade circuit, is situated after autogenous (AG) milling (van Niekerk et al., 2013), where a DMS/bulk sorter sizing screen is utilized to separate the XRT feed envelope from the $-8 \mathrm{~mm}$ DMS feed. Any $-1.5 \mathrm{~mm}$ fine effluent generated in the circuit due to particle breakdown by materials handling, transfers, and recycling is also separated.

\footnotetext{
* DRA Mineral Projects, Johannesburg, South Africa.

+ Tomra Sorting Solutions, Randburg, South Africa.

\# Mineral Resources, Lucara Diamond Corp, Vancouver BC, Canada.

\& Karowe Diamond Mine, Letlhakane, Botswana.

(C) The Southern African Institute of Mining and Metallurgy, 2016. ISSN 2225-6253. This paper was first presented at the Diamonds still Sparkling 2016 Conference, 14-17 March 2016, Gaborone International Convention Centre.
} 


\section{Pioneering large diamond recovery at Karowe diamond mine}

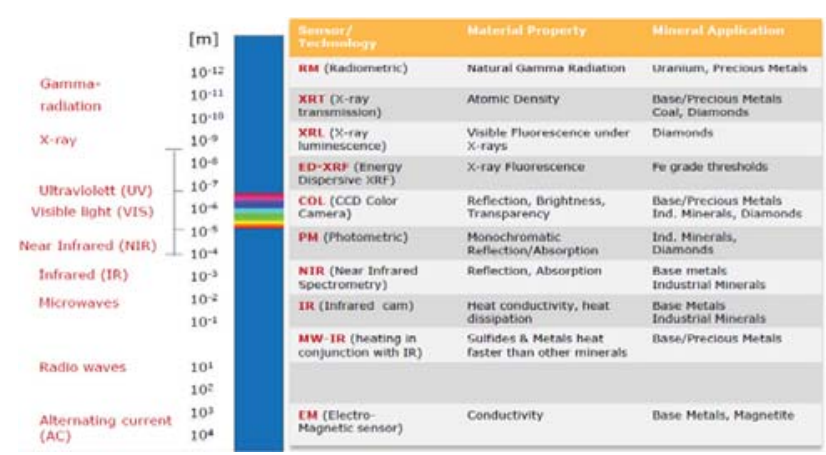

Figure 1-Sensor technology applications (von Ketelhodt, 2012)

XRT-imaging sensors measure the $x$-ray flux after the rays have passed through matter The flux depends on the atomic density, specific density and thickness of matter.

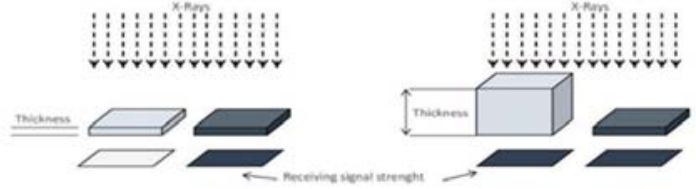

Problem: Two pieces of different materials can create the same flux. Solution: Dual Energy $X$-ray Transmission

Figure 2-Principle of material discrimination by XRT sorter

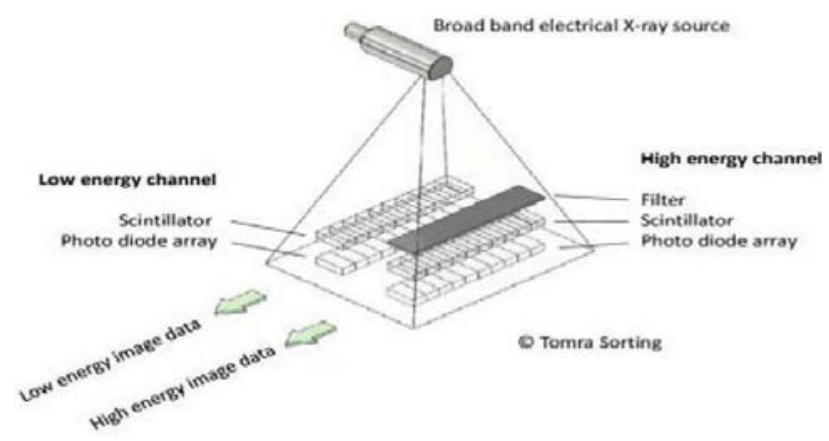

Figure 3-Dual XRT sensing

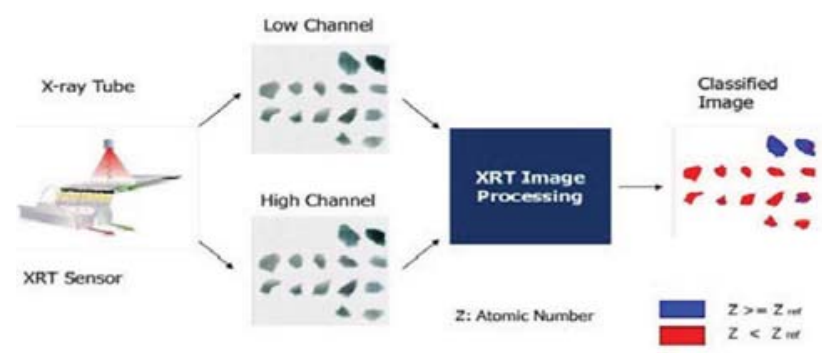

Figure 4-XRT imaging (Riedel and Dehler, 2010)

The DMS/bulk sorter sizing screen is key to the circuit (Figures 6, 7, and 8) due to its central positioning in receiving milled ore, tertiary crusher product, and pebble crusher 'bleed' fraction (pebble crusher recycle bypass not redirected back to mill feed for load management requirements). From the DMS/bulk sorter sizing screen, the feed is split into the following three streams:

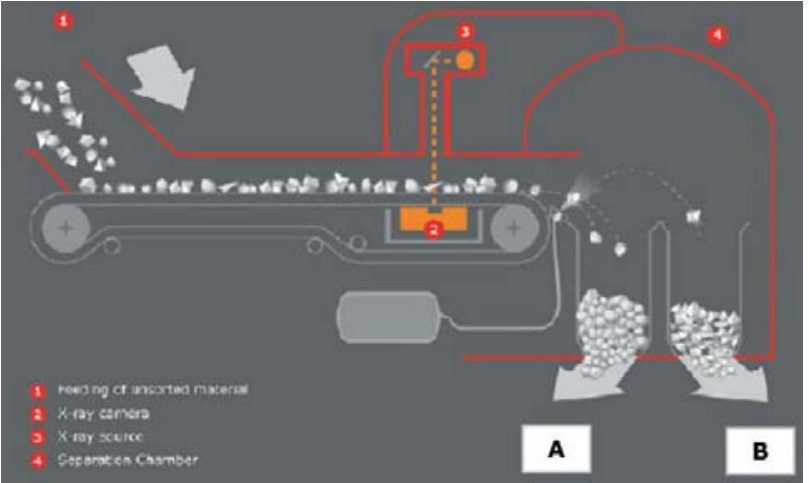

Figure 5-XRT automated sorting principle

$>-60+8 \mathrm{~mm}$ fraction, which is wet-screened and fed to the XRT section

$>-8+1.5 \mathrm{~mm}$ fraction, which is wet-screened and fed to the existing DMS for gravity concentration

$>-1.5 \mathrm{~mm}$ envelope, which is removed as effluent to the degrit circuit for grit removal and dewatering. There is little to no value in the effluent stream, hence the reason for removal and dewatering.

In the XRT section, the $-60+8 \mathrm{~mm}$ is further separated via the bulk sorter sizing screen at the top of the XRT building into the following streams:

> Large diamond recovery (one stream) $-60+32 \mathrm{~mm}$

> Coarse XRT (two streams) $-32+14 \mathrm{~mm}$

$>$ Middles XRT (two streams) $-14+8 \mathrm{~mm}$.

To recover large diamonds in the various XRT size fractions as described above, the processing route for each individual size fraction stream utilizes bins and variablespeed belt feeders to 'match' each associated XRT sorter's size-specific throughput. Feed presentation ahead of each XRT machine was a critical factor evaluated during the design phase: a vibrating feeder ahead of the XRT machine accepts feed from the upstream belt feeder and introduces an evenly distributed monolayer feed to the XRT feed belt, which typically runs at speeds of up to $3 \mathrm{~m} / \mathrm{s}$. Table I illustrates the throughput to size fraction relationship applicable to Karowe's bulk sorting section.

Feed moisture content from upstream washing/sizing was also crucial to the design, as more than $8 \%$ surface moisture (by weight) will cause unnecessary build-up of fines in the bulk sorting section and detrimentally affect the machine's performance. Supporting utility services were also essential in order for each sorter to perform at its optimum efficiency - by utilizing compressed air and chilled water as essential services to the machines, diamond concentrate could be adequately 'ejected' from each sized stream with chiller water, effectively cooling the X-ray tubes for continuous successful operation. Tables II and III capture the chiller water and compressed air services data. The data was developed during design and subsequent operation of the Karowe XRT sorter machines.

Cold commissioning of the Karowe XRT machines was completed on 15 April 2015. This included the following vendor-specific activities:

> Splicing of new sorter belts 


\section{Pioneering large diamond recovery at Karowe diamond mine}

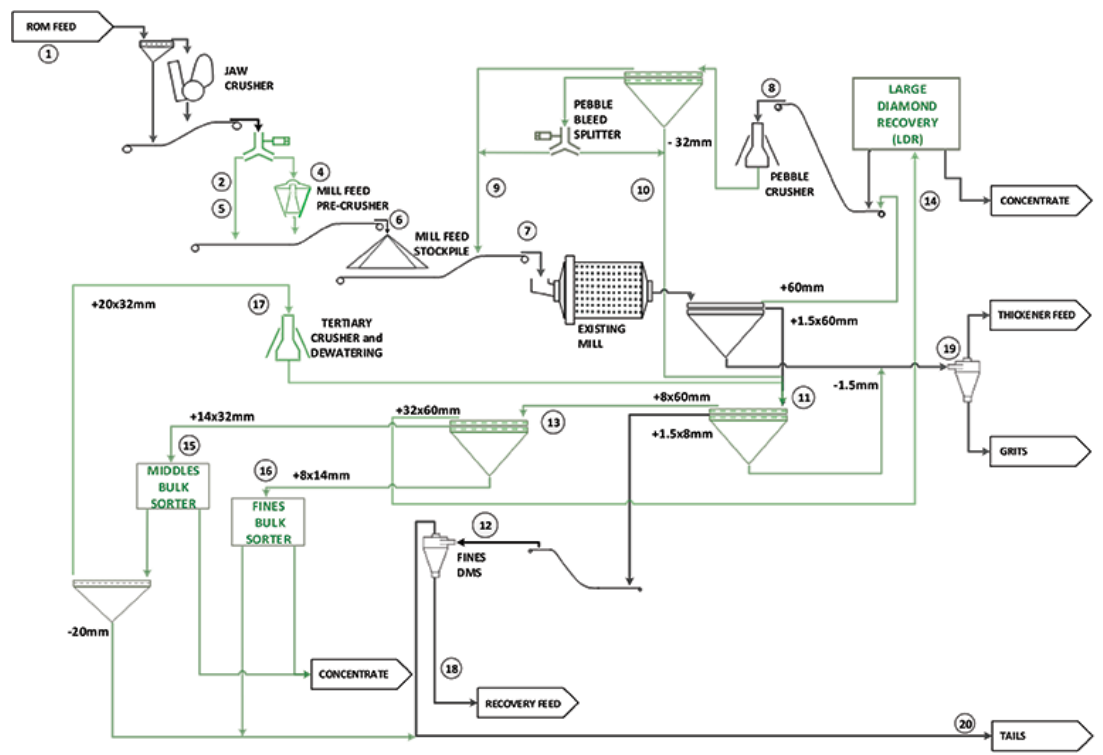

Figure 6-XRT treatment section in relation to the Karowe Plant Upgrade Project circuit (Morgan et al., 2015)

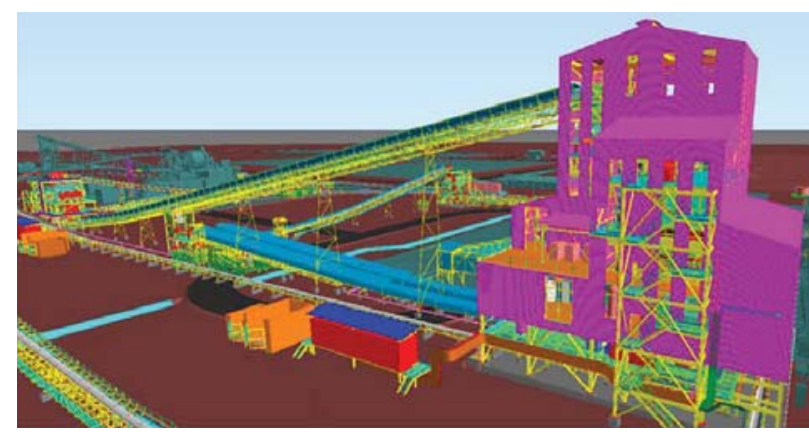

Figure 7-3D model of Karowe's XRT section (in foreground, with purple shading)

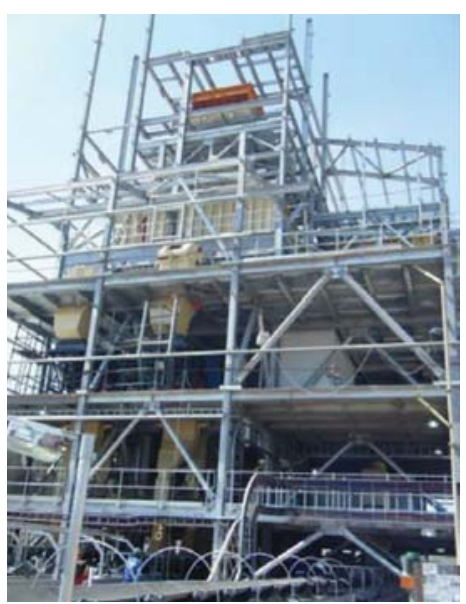

Figure 8-Karowe's XRT section during construction in Q2 2015

- Electrical wiring of the sorters

> Sorter calibrations and sorting algorithms

> Tracer testing without material

> Diamond testing without material.

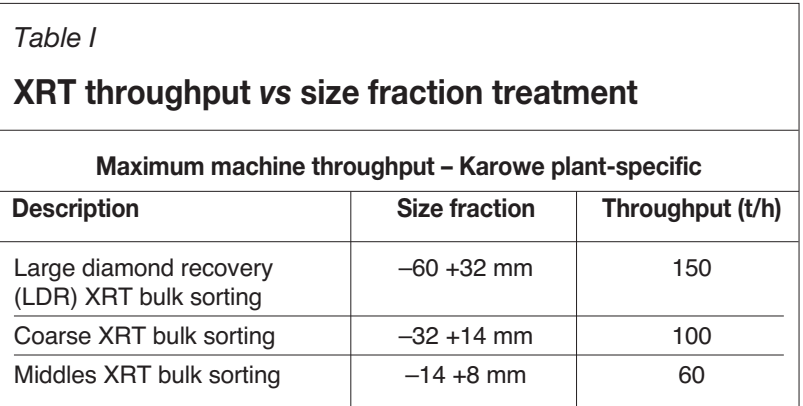

Table II

Chiller water requirements per Karowe XRT sorter

\begin{tabular}{|l|c|}
\hline Description & Value/comment \\
\hline Water circuit flow rate (I/min) & 10 \\
\hline Water pressure at machine inlet (bar) & 4.5 \\
\hline Maximum operating temperature $\left({ }^{\circ} \mathrm{C}\right)$ & 40 \\
\hline $\begin{array}{l}\text { Water inlet temperature }\left({ }^{\circ} \mathrm{C}\right) \\
\text { (Chiller pipes require isolation lagging to keep } \\
\text { fluid temperature to a minimum before feed } \\
\text { entry into machines) }\end{array}$ & 25 \\
\hline $\begin{array}{l}\text { Cooling capacity required } \\
\text { (kW, accumulated heating energy) } \\
4 \mathrm{~kW} \text { X-ray source }\end{array}$ & \\
$4 \mathrm{~kW}$ generator & \\
\hline Coolant & High glycol content; \\
\end{tabular}

During the tracer and diamond testing without material, the tracer and diamond quantities with specifications in Table IV were utilized to calibrate, set up, and test the performance of individual machines. Aspects requiring set-up and testing included white balance, nozzle to pixel mapping, divergence, and establishing the various calibration curves. 


\section{Pioneering large diamond recovery at Karowe diamond mine}

\begin{tabular}{|l|c|}
\hline $\begin{array}{l}\text { Table III Consumed air requirements per ton of feed ejected } \\
\text { Description }\end{array}$ & Value \\
\hline Large diamond recovery (LDR) XRT bulk sorting $(\mathrm{m} 3 / \mathrm{h})$ & (Based on $1 \%$ material ejection rate) \\
\hline Coarse XRT $\left(\mathrm{m}^{3} / \mathrm{h}\right)$ & (Based on $1 \%$ material ejection rate) \\
\hline Middles XRT $\left(\mathrm{m}^{3} / \mathrm{h}\right)$ & (Based on $1 \%$ material ejection rate) \\
\hline Operating air pressure (bar) & $9.5-10.0$ \\
\hline
\end{tabular}

Table IV

Karowe XRT tracer and diamond specifications used during cold commissioning

\begin{tabular}{|l|c|c|c|}
\hline Material size fraction (mm) & Number of cubic carbon tracers used & Tracer dimensions (mm) & Minimum diamond size range (mm) \\
\hline $\begin{array}{l}\text { LDR: }-60+32 \mathrm{~mm} \text { at } 150 \mathrm{t} / \mathrm{h} \\
\begin{array}{l}\text { Coarse: }-32+14 \mathrm{~mm} \text { at } 100 / 200 \mathrm{t} / \mathrm{h} \\
\text { (throughput per sorter / overall throughput) }\end{array}\end{array}$ & 500 at $98 \%$ expected recovery & $50 \times 50 \times 50$ & $24.26 \times 20.12 \times 24.12$ (tracer diamond \#52) \\
\hline $\begin{array}{l}\text { Middles: }-14+8 \mathrm{~mm} \text { at } 43 / 86 \mathrm{t} / \mathrm{h} \\
\text { (throughput per sorter / overall throughput) }\end{array}$ & 500 at $98 \%$ expected recovery & $15 \times 15 \times 15$ & $11.14 \times 11.03 \times 9.51$ (tracer diamond \#25) \\
\hline
\end{tabular}

Table $\mathrm{V}$

\section{Karowe LDR $(-60+32 \mathrm{~mm})$ XRT sorter tracer test results}

\begin{tabular}{|c|c|c|c|c|c|}
\hline Tracer test no. & $\begin{array}{l}\text { Totalizer } \\
\text { start (t) }\end{array}$ & $\begin{array}{l}\text { Totalizer } \\
\text { stop (t) }\end{array}$ & $\begin{array}{l}\text { Tons treated during } \\
\text { tracer test }\end{array}$ & $\begin{array}{l}\text { Number of tracers } \\
\text { added to ore feed }\end{array}$ & $\begin{array}{l}\% \text { tracer } \\
\text { recovery }\end{array}$ \\
\hline 1 & 5.8 & 14.0 & 8.2 & 100 & 100 \\
\hline 2 & 14.0 & 26.2 & 12.2 & 100 & 100 \\
\hline 3 & 26.2 & 33.9 & 7.7 & 100 & 100 \\
\hline 4 & 33.9 & 46.5 & 12.6 & 100 & 100 \\
\hline 5 & 46.5 & 54.3 & 7.8 & 100 & 100 \\
\hline Total / average & - & - & 48.5 (total) & 500 (total) & 100 (average) \\
\hline Average throughput range during all tracer test runs $(\mathrm{t} / \mathrm{h})$ & \multicolumn{5}{|c|}{$100-153$} \\
\hline \% VSD setting on belt feeder feeding XRT sorter & \multicolumn{5}{|c|}{20 (tests 1,2 ) and $38-42$ (Tests 3,4 , and 5) } \\
\hline
\end{tabular}

Following cold commissioning, which was completed on 15 April, the project moved into a hot commissioning phase with the following activities:

$>$ Tracer testing with material feed

$>$ Production ramp-up

$>$ Production optimization.

Tracer results obtained during hot commissioning of the XRT sorters can be seen in Tables V to IX.

Average yields achieved during tracer tests in material feed were in the order of $1.3-8.0 \times 10^{-5} \%$, with an associated calculated product yield range of $0.3-1.2 \mathrm{~kg} / \mathrm{d}$. Hot commissioning was completed on 27 April 2015, and the XRT sorters were handed over to the client for normal production running. Production performance monitoring continued after XRT handover for a further 28 days. Further XRT optimization was required to address the challenges experienced post-production running. These challenges were:

> Low air consumption and air inlet pressure: mitigating action involved separating the LDR XRT separator from the rest of the XRT compressed air circuit with its own dedicated compressor unit
Low chiller water inlet flow: matter resolved on-site through small system adjustments

> Occasional fines carry-over from DMS/bulk sorter sizing screen: this was alleviated by optimizing the spray and wash water requirements associated upstream with the DMS/bulk sorter sizing screen.

On 18 November 2015, Karowe mine made history when Lucara Diamond Corporation reported the recovery of an 1111 carat, white Type IIa stone weighing $222 \mathrm{~g}$ and measuring $65 \mathrm{~mm} \times 56 \mathrm{~mm} \times 40 \mathrm{~mm}$ (Financial Post, 2015). This is the second-largest gem-quality stone in history beaten only by the massive Cullinan diamond discovered in 1905 and weighing 3106 carats. Karowe mine also recovered an 813 carat, white Type Ila diamond soon after the 1111 carat find - which is the sixth-largest gem-quality stone also ever recovered.

\section{Future XRT upgrades envisaged at Karowe mine}

Due to the prevalence of very large diamonds at Karowe, the mine has opted to evaluate the possibility of a very large 


\section{Pioneering large diamond recovery at Karowe diamond mine}

Table VI
Karowe Coarse $\mathbf{1} \mathbf{( - 3 2 + 1 4} \mathbf{~ m m}) \mathbf{X R T}$ sorter tracer test results
\begin{tabular}{|l|c|c|c|c|c}
\hline Tracer test no. & $\begin{array}{c}\text { Totalizer } \\
\text { start } \mathbf{t})\end{array}$ & $\begin{array}{c}\text { Totalizer } \\
\text { stop } \mathbf{t})\end{array}$ & $\begin{array}{c}\text { Tons treated during } \\
\text { tracer test }\end{array}$ & $\begin{array}{c}\text { Number of tracers } \\
\text { added to ore feed }\end{array}$ & $\begin{array}{c}\% \text { tracer } \\
\text { recovery }\end{array}$ \\
\hline 1 & 12.4 & 18.6 & 6.2 & 100 & 100 \\
\hline 2 & 18.6 & 24.1 & 5.5 & 100 & 100 \\
\hline 3 & 24.1 & 29.0 & 4.9 & 100 & 100 \\
\hline 5 & 29.0 & 33.6 & 4.6 & 100 & 100 \\
\hline Total / average & 33.6 & 37.4 & 3.8 & 100 & 100 \\
\hline Average throughput range during all tracer test runs (t/h) & - & - & 25.0 (total) & 500 (total) & 100 (average) \\
\hline$\%$ VSD setting on belt feeder feeding XRT sorter & & & $100-120$ & & \\
\hline
\end{tabular}

Table VII

Karowe Coarse $2(-32+14 \mathrm{~mm})$ XRT sorter tracer test results

\begin{tabular}{|c|c|c|c|c|c|}
\hline Tracer test no. & $\begin{array}{l}\text { Totalizer } \\
\text { start (t) }\end{array}$ & $\begin{array}{l}\text { Totalizer } \\
\text { stop (t) }\end{array}$ & $\begin{array}{c}\text { Tons treated during } \\
\text { tracer test }\end{array}$ & $\begin{array}{l}\text { Number of tracers } \\
\text { added to ore feed }\end{array}$ & $\begin{array}{l}\% \text { tracer } \\
\text { recovery }\end{array}$ \\
\hline 1 & 3.0 & 8.8 & 5.8 & 100 & 100 \\
\hline 2 & 8.8 & 13.8 & 5.0 & 100 & 100 \\
\hline 3 & 13.8 & 18.6 & 4.8 & 100 & 100 \\
\hline 4 & 18.6 & 24.8 & 6.2 & 100 & 100 \\
\hline 5 & 24.8 & 29.4 & 4.6 & 100 & 100 \\
\hline Total / average & - & - & 26.4 (total) & 500 (total) & 100 (average) \\
\hline Average throughput range during all tracer test runs $(\mathrm{t} / \mathrm{h})$ & \multicolumn{5}{|c|}{$90-130$} \\
\hline \% VSD setting on belt feeder feeding XRT sorter & \multicolumn{5}{|c|}{25} \\
\hline
\end{tabular}

Table VIII

Karowe Middles $1(-14+8 \mathrm{~mm})$ XRT sorter tracer test results

\begin{tabular}{|c|c|c|c|c|c|}
\hline Tracer test no. & $\begin{array}{l}\text { Totalizer } \\
\text { start (t) }\end{array}$ & $\begin{array}{l}\text { Totalizer } \\
\text { stop (t) }\end{array}$ & $\begin{array}{c}\text { Tons treated during } \\
\text { tracer test }\end{array}$ & $\begin{array}{l}\text { Number of tracers } \\
\text { added to ore feed }\end{array}$ & $\begin{array}{l}\% \text { tracer } \\
\text { recovery }\end{array}$ \\
\hline 1 & 34.8 & 38.3 & 3.5 & 100 & 100 \\
\hline 2 & 38.3 & 41.0 & 2.7 & 100 & 98 \\
\hline 3 & 41.0 & 44.3 & 3.3 & 100 & 100 \\
\hline 4 & 44.3 & 47.0 & 2.7 & 100 & 100 \\
\hline 5 & 47.0 & 49.4 & 2.4 & 100 & 99 \\
\hline Total / average & - & - & 14.6 (total) & 500 (total) & 99.4 (average) \\
\hline Average throughput range during all tracer test runs $(\mathrm{t} / \mathrm{h})$ & \multicolumn{5}{|c|}{$40-43$} \\
\hline$\%$ VSD setting on belt feeder feeding XRT sorter & \multicolumn{5}{|c|}{13} \\
\hline
\end{tabular}

Table IX

Karowe Middles $2(-14+8 \mathrm{~mm})$ XRT sorter tracer test results

\begin{tabular}{|c|c|c|c|c|c|}
\hline Tracer test no. & $\begin{array}{l}\text { Totalizer } \\
\text { start (t) }\end{array}$ & $\begin{array}{l}\text { Totalizer } \\
\text { stop (t) }\end{array}$ & $\begin{array}{c}\text { Tons treated during } \\
\text { tracer test }\end{array}$ & $\begin{array}{l}\text { Number of tracers } \\
\text { added to ore feed }\end{array}$ & $\begin{array}{l}\% \text { tracer } \\
\text { recovery }\end{array}$ \\
\hline 1 & 46.9 & 50.9 & 1.3 & 100 & 100 \\
\hline 2 & 50.9 & 52.1 & 1.2 & 100 & 100 \\
\hline 3 & 52.1 & 53.3 & 1.2 & 100 & 99 \\
\hline 4 & 53.3 & 54.6 & 1.3 & 100 & 100 \\
\hline 5 & 54.6 & 55.8 & 1.2 & 100 & 100 \\
\hline Total / average & - & - & 6.2 (total) & 500 (total) & 99.8 (average) \\
\hline Average throughput range during all tracer test runs (t/h) & \multicolumn{5}{|c|}{$41-44$} \\
\hline$\%$ VSD setting on belt feeder feeding XRT sorter & \multicolumn{5}{|c|}{13} \\
\hline
\end{tabular}




\section{Pioneering large diamond recovery at Karowe diamond mine}

diamond recovery (VLDR) section close to the current secondary crushing area. A potential design would entail keeping the sorting and comminution aspects separate from a process perspective, so that the undersize scalping associated with comminution can be changed independently of the VLDR sorter. In a nutshell, a proposed design will consider:

- Scalping of all primary crusher ROM product at $60 \mathrm{~mm}$ or even $50 \mathrm{~mm}$, with the $-60 / 50 \mathrm{~mm}$ undersize reporting directly to the AG mill

> Inclusion of a $125 \mathrm{~mm}$ grizzly screen ahead of secondary crushing to treat the oversize fraction from the scalping screen, with the $-125+50 \mathrm{~mm}$ middles envelope directed to the VLDR sorter(s) for diamond recovery

> Tailings from the new VLDR sorter(s) will subsequently recombine with the $+125 \mathrm{~mm}$ grizzly oversize material and be subjected to the existing proportional splitter ahead of the secondary crushing section, undergoing the same crusher/bypass operational split flexibility of 25,50 , or $75 \%$ as is currently the case.

\section{Acknowledgements}

The authors are grateful to the following individuals:

> William Lamb, Lucara Diamond Corp

> Paul Day, Lucara Diamond Corp

> Gerald Ndlovu, Boteti Mining

> John Maketo, Boteti Mining

> Boteti Process, Lab, and Security teams
> Fabien Riedel, Tomra Sorting Solutions

> Geoffrey Madderson, Tomra Sorting Solutions

> Gavin Underwood, Minopex Botswana

> Paul Morgan, DRA Mineral Projects

> Matthew Duddy, DRA Mineral Projects

> Bennie Viljoen, DRA Mineral Projects

> Reuben Moalosi, DRA Mineral Projects

> Cornelius Ntsomeng, DRA Mineral Projects

- Gavin Outhwaite, DRA Mineral Projects

$>$ DRA construction and commissioning teams.

\section{References}

FinANCiAL Post. 2015. Canadian miner Lucara finds 1,111-carat diamond believed to be second largest ever. http://business.financialpost.com/ news/mining/canadian-miner-lucara-uncovers-1111-carat-diamondbelieved-to-be-second-largest-ever-found [Accessed 14 Dec. 2015].

Morgan, P., VAN NieKerk, L.M., Underwood, G., and PAZ, A. 2015. Introduction of Turbo-lifter System at Karowe Diamond Mine and comminution circuit upgrade. Proceedings of the Sixth International Conference on Semiautogenous and High Pressure Grinding Technology. Vancouver, Canada.

RIEDEL, F. and DeHLER, M. 2010. Recovery of unliberated diamonds by X-ray transmission sorting. Proceedings of the Fourth Diamonds: Source to Use Conference, Gaborone, Botswana. Southern African Institute of Mining and Metallurgy, Johannesburg. pp. 193-200.

VAn NiEKerK, L.M., NdLovu, G.N., and SiKWA, N.A. 2013. Commissioning and operating an autogenous mill at Karowe Diamond Mine. Proceedings of the Fifth Diamonds: Source to Use Conference, Muldersdrift, South Africa. Southern African Institute of Mining and Metallurgy, Johannesburg. pp. 175-192.

Von Ketelhodt, L. 2012. Presentation: Tomra Sorting Solutions. Regional Meeting. Southern African Institute of Mining and Metallurgy, Johannesburg. 